\title{
O direito à liberdade: uma visão sobre a perspectiva dos direitos fundamentais
}

Thiago Ruiz

\section{Resumo}

O homem por si mesmo é livre. A liberdade nasce juntamente com o ser humano, entretanto, são impostas restrições à liberdade do homem em razão de sua opção de conviver em sociedade. Portanto, face a ratio do espírito do homem ser livre e do homem ser um animal social, a liberdade inerente ao ser humano é conjunturada no depósito do direito. A ascensão das liberdades e garantias frente ao direito e seu desenvolvimento dogmático jurídico-penal e político-criminal é decorrente de conquistas que possuem estirpes no pensamento filosófico, no racionalismo de Descartes e no individualismo liberal, que fizeram emergir subsídios para que se tutelasse a dignidade da pessoa humana. Percorrido a vereda em que se levou ao Estado reconhecer e resguardar a dignidade do ser humano, esta foi eleita como fundamento do Estado Social e Democrático de Direito, o que findou em constituir a liberdade como direito fundamental do homem, objetivando como primaz a sua proteção e limites.

Palavras Chave: Liberdade; Direitos fundamentais; Direito à liberdade.

\section{0 direito à liberdade}

Hodiernamente, é indiscutível a relevância que se dá aos direitos fundamentais dentro de uma ordem jurídica. Recebem merecido destaque em relação a outras normas, legando às demais patamares hierarquicamente inferiores. Segundo Guerra ${ }^{1}$, a lei deixou de ser o centro do universo jurídico em detrimento dos direitos fundamentais, que formam uma nova categoria jurídica, um regime jurídico específico. Gonçalves ${ }^{2}$, não menos audacioso, elege estes direitos como pedra angular de todo o alicerce jurídico político.

Por se tratar de tema complexo e de constante evolução histórica e jurídica tornase tarefa árdua conceituar direito fundamental, todavia, assume este risco Moraes ${ }^{3}$, ao dar a seguinte posição semântica de caráter ontológico: os direitos fundamentais "resultam em

1 GUERRA, Marcelo Lima. Direitos fundamentais e a proteção do credor na execução civil. São Paulo: Revista dos Tribunais, 2003. P. 82.

2 GONÇALVES, Flávio José Moreira. Notas para a caracterização epistemológica da teoria dos direitos fundamentais. In Guerra Filho, Willis Santiago. Dos direitos humanos aos direitos fundamentais. Porto Alegre: Livraria do Advogado, 1997. p. 35.

3 MORAES, Guilherme Peña de.Direitos fundamentais: conflitos e soluções. Niterói: Labor Júris, 2000. p. 11. 
posições jurídicas das pessoas enquanto tais, com eficácia no âmbito das relações com o Estado ou entre particulares, consubstanciadas ou não na Constituição". O insigne italiano Norberto Bobbio ${ }^{4}$ salienta esta dificuldade, ao tratar sobre os direitos do homem, como uma das antíteses na busca de fundamento absoluto para os direitos humanos.

Para melhor compreensão e delimitação do tema, se faz mister diferenciar direitos fundamentais e direitos humanos com o escopo de conhecer o alcance de cada uma destas expressões. Bastos ${ }^{5}$ denomina os direitos humanos, como "liberdades públicas", há ainda, quem as chame de liberdades individuais, garantias individuais, entre outras. Bobbio cita outros três empecilhos à "ilusão" do fundamento absoluto, que se referem: os direitos dos homens constituírem uma classe invariável, por ser heterogênea; e, finalmente, por revelar uma antinomia entre os direitos invocados.

Por simples divisão, direitos fundamentais são aqueles que decorrem da ordem jurídica positivada, são os direitos positivados a nível interno, conforme ensina Luño ${ }^{6}$. 0 autor continua, afirmando que direitos humanos são aqueles que têm ascendência na natureza humana: "Los derechos naturales positivados em lãs declaraciones y convenciones internacionales, así como aquelas exigencias basicas relacionadas com la dignidad, libertad y igualdad de la persona que no han alcanzado um estatuto jurídico-positivo" ${ }^{7}$. Importante ressalva faz Moraes ${ }^{8}$ ao salientar que todos os direitos concernentes à sua fundamentalidade podem ser qualificados como direitos humanos, subtraindo os que fazem referências às pessoas jurídicas.

O jurista lusitano Miranda ${ }^{9}$ ensina que "os direitos fundamentais, ou pelo menos os imediatamente conexos com a dignidade da pessoa humana, radicam no Direito natural". Isto posto, os direitos fundamentais têm relações diretas ou indiretas com os direitos humanos à medida que são constituídos em decorrência daqueles. São conseqüências no plano jurídico, principalmente no constitucional, do desenvolvimento histórico, político e social dos direitos humanos, buscando aplicabilidade e proteção legal dos mesmos.

4 BOBBIO, Norberto. A era dos direitos. Trad. Carlos Nelson Coutinho. 12. ed. Rio de Janeiro: Campus, 1992. p. 17-22.

5 BASTOS, Celso Ribeiro. Curso de direito constitucional. 20. ed. São Paulo: Saraiva, 1999. p. 165.

6 LUÑO APUD GARCIA, Maria. Mas, quais são os direitos fundamentais?. Revista de Direito Constitucional e Internacional. São Paulo: Revista dos Tribunais, n. 39, 2002. p. 115-123.

Idem. Ibiden.

8 MORAES, 2000. p. 16

9 MIRANDA, Jorge. Manual de direito constitucional. 3. ed. tomo. IV. Coimbra: Coimbra, 2000. p. 53. 
Elucida Miranda ${ }^{10}$ que há uma dicotomia em relação à formação dos direitos fundamentais, dividem-se, assim, direitos fundamentais em sentido formal e direitos fundamentais em sentido material.

Em sentido formal são aqueles participantes da Constituição formal, encontram-se positivados no texto constitucional. Em contrapartida, os direitos fundamentais em sentido material são aqueles que não estão declarados de forma expressa, são implícitos, resultam do sentimento jurídico coletivo, do ideal de Direito, são constantes das leis ordinárias e das normas de direito internacional.

A Constituição brasileira prevê a aplicação de ambos, sendo que os direitos fundamentais em sentido material estão previstos no art. 5으, §2으, o qual reza que os direitos fundamentais que não são previstos na CF não são excluídos por aqueles que estão expressos em seu texto.

Com o escopo de delimitar quais são os direitos fundamentais, tiremos por base, primeiramente, o modo de divisão alçado no texto constitucional. O Título II foi denominado Dos Direitos e Garantias Fundamentais; o Capítulo I, art. 5으, diz Dos Direitos e Deveres Individuais e Coletivos; o Capítulo II, art. 6을 usque art. 11으, menciona Dos Direitos Sociais; o Capítulo III, art. 12ㅇ e 13으, Da Nacionalidade; o Capítulo IV, arts. 14으 a 16으, Dos Direitos Políticos; e, finalmente, o Capítulo V, art. 17ํㅡ, Dos Partidos Políticos. A Constituição adotou o regime constitucional de direitos fundamentais.

Através dos critérios identificadores de Lassalle $^{11}$ em ensaio sobre quais são os direitos fundamentais, Garcia ${ }^{12}$ busca identificar estas leis fundamentais. Conclui a autora que o caput do art. 5 da Constituição especifica os seguintes direitos fundamentais básicos: vida, liberdade, igualdade, segurança e propriedade.

Estes direitos fundamentais básicos constituem o alicerce de todos os demais direitos consagrados nos incisos do art. 5으, nos artigos seqüenciais do Título II, bem como nos demais dispositivos constitucionais. Termina por afirmar que em virtude do $§ 2 \circ$ do art.

\footnotetext{
10 Idem. p. 7-12.

11 O primeiro critério que Ferdinand Lassalle propõe é que a lei fundamental é uma lei básica, o segundo critério diz que esta lei fundamental seja verdadeiro fundamento de outras leis, e o último fundamento é que essas leis se regem pela necessidade ativa, isto é, há uma força eficaz e determinante que atua sobre tudo o que na lei fundamental se baseia.

12 GARCIA, 2002. p. 120-122.
} 
$5^{\mathbf{0}^{13}}$, relativo aos direitos fundamentais não expressos, somente os direitos e garantias vinculados a um dos cinco direitos fundamentais básicos completam a classificação de direitos fundamentais, os demais direitos apenas são normas constitucionais.

Podemos concluir, através do estudo de $\mathrm{Garcia}^{14}$, que a liberdade é um direito fundamental básico por fruir do caput do art. 5ㅇ.

Os direitos fundamentais são resultado de um desenvolvimento histórico da relação entre o homem e o Estado decorrente de um processo lento de conquistas e retrocessos. 0 surgimento dos direitos fundamentais é devido à aparição do Estado Liberal, no século XIX, entretanto iniciou sua trajetória evolucionista muito antes.

No princípio o poder estatal era ilimitado. O marco inicial em que o Estado cede seu totalitarismo em benefício dos homens foi a Carta Magna do Rei João Sem Terra, em 1215, acordo em que confirmou a supremacia monárquica mediante concessões aos súditos. Importante avanço aconteceu com as Declarações Americanas, a partir da independência das colônias, a mais relevante é a Declaração de Direitos do Bom Povo de Virgínia de 1776.

Nesta mesma época outra importante colaboração para o desenvolvimento dos direitos fundamentais decorreu da Declaração dos Direitos do Homem e do Cidadão, de 1789, em função da Revolução Francesa. Também contribuiu a Declaração do Povo Trabalhador e Explorado, de 1918, consubstanciada nas formulações socialista de Marx, Engels e Lênin e pautada na Revolução Russa.

E ainda, em 1948, após a Segunda Grande Guerra, surgiu a Declaração Universal dos Direitos do Homem.

As declarações de direito, informa Afonso da Silva ${ }^{15}$, surgiram na forma de proclamações solenes que estatuariamente numeravam os direitos. Em seguida, passaram a constar dos preâmbulos das Constituições, especialmente em França, adquiriu natureza concreta de normas jurídicas positivas constitucionais.

13 Art. 5으 § 2으, CF. "Os direitos e garantias expressos nesta Constituição não excluem outros decorrentes do regime e dos princípios por ela adotados, ou dos tratados internacionais em que a República Federativa do Brasil seja parte".

14 GARCIA, 2002. p. 122-123.

15 SILVA, José Afonso da. Curso de direito constitucional positivo. 20. ed. São Paulo: Malheiros, 2002. p. 175. 
A doutrina clássica classifica os direitos fundamentais em gerações ${ }^{16}$, conforme a ordem de aparecimento ao longo da história. Os direitos de primeira geração são aqueles, que se vislumbraram com a formação do Estado Liberal, surgiram no século XVIII, foram os primeiros direitos do homem positivados nas declarações. O indivíduo é o titular. Caracterizam uma oposição ao Estado frente ao totalitarismo.

Compreendem a tutela da vida, liberdade, igualdade, propriedade, segurança, associação, entre outros. Os direitos de segunda geração datam do século XIX, basearam-se no desenvolvimento econômico, industrial e no surgimento do proletariado, fundaram-se nos direitos econômicos e sociais.

Também os direitos culturais surgiram neste período. Encampam os direitos sociais, isto é, o direito ao trabalho, à saúde, à moradia, à educação. Por último, os direitos de terceira geração, também denominados direitos de solidariedade, são os direitos difusos. Pertencem a esta geração os direitos ao meio ambiente equilibrado, a paz, ao desenvolvimento, os direitos do consumidor e das crianças e dos adolescentes.

Com a finalidade de comparar os direitos fundamentais e os direitos humanos, Bobbio $^{17}$ distingue três fases na história da formação das declarações de direitos. A primeira fase é a teórica filosófica em que os direitos humanos se baseiam em John Locke e Jacques Rousseau.

A fase segunda é o momento da Declaração dos Direitos do Homem pela ONU em 1948. A terceira fase dá-se pela universalidade dos destinatários dos direitos e a positivação destes direitos reconhecidos.

\section{Características dos direitos fundamentais}

Aos direitos fundamentais são imanentes certos caracteres. Para tanto, esses predicados possuem ascendência no desenvolvimento durante séculos dos direitos ligados à dignidade humana.

Vejamos os caracteres gerais dos direitos fundamentais.

16 LOPES, Ana Maria D’Ávila. Hierarquização dos direitos fundamentais?. Revista de Direito Constitucional e Internacional. São Paulo: Revista dos Tribunais, n. 34, 2001. p. 174-177.

17 BOBBIO, 1992. p. 28-30. 
Algumas características dos direitos fundamentais emergem do próprio texto constitucional. Caracterizam-se pela sua aplicabilidade imediata ${ }^{18}$, poderíamos chamálas de normas auto-aplicáveis.

Lopes ${ }^{19}$ prevê o caráter de progressividade, da seguinte forma: "os direitos da primeira geração possuem aplicabilidade imediata, os da segunda e terceira gerações estão sujeitos a uma progressividade, traduzida em normas programáticas cuja aplicação concreta encontra-se condicionada ao desenvolvimento de políticas legislativas posteriores, que Ihes darão viabilidade material".

Também, são caracterizadas por serem dogmatizadas como cláusulas pétreas ${ }^{20}$, ou seja, não podem ser objeto de reforma constitucional, são intangíveis por emendas. Lopes ${ }^{21}$ denomina os direitos fundamentais de irrevogáveis.

O constitucionalista Afonso da Silva ${ }^{22}$ ao citar os caracteres dos direitos fundamentais informa que este tema foi desenvolvido pelas concepções jusnaturalistas, de onde afirma ser estes direitos inatos, absolutos, invioláveis e imprescritíveis. Ainda completa reconhecendo que estes direitos são baseados na historicidade, inalienabilidade, imprescritibilidade e irrenunciabilidade.

Ao propor um regime geral dos direitos fundamentais o ilustre constitucionalista português Canotilho ${ }^{23}$ salienta o caráter intemporal e universal destes direitos. Isto é, estes direitos são garantidos a qualquer tempo, para todos os povos.

Canotilho consagra as funções dos direitos fundamentais sobre o prisma de que eles têm: primeiramente, a função de defesa ou de liberdade, proibindo o poder público de ingerir na vida jurídica individual do cidadão e de proporcionar positivamente os direitos fundamentais. Em segundo, a função de prestação social, isto é, o Estado deve proporcionar ao particular saúde, educação e segurança, em sentido estrito. A terceira se dá pela função de proteção do indivíduo perante terceiros, como o asilo inviolável e o direito à vida que

18 Art. 5o, § 1ํ, CF. "As normas definidoras dos direitos e garantias fundamentais têm aplicação imediata".

19 LOPES, 2001. p. 180.

20 Art. 60, CF. “A Constituição poderá ser emendada mediante proposta. § 4ํ. Não será objeto de deliberação a proposta de emenda tendente a abolir: inc. IV - os direitos e garantias individuais".

21 LOPES, 2001. p. 177-179.

22 SILVA, 2002. p. 181. Ressalva José Afonso da Silva que quanto ao caráter absoluto "se reconhecia neles no sentido de imutabilidade, não pode mais ser aceito desde que se entenda que tenham caráter histórico". No mesmo sentido MORAES, 2000. p. 27-34.

23 CANOTILHO, José Joaquim Gomes. Direito constitucional e teoria da constituição. Coimbra: Almedina, 1997. p. 359. 
deve ser protegido em face de eventuais agressões de outros indivíduos. E finalmente, a função de não discriminação, que nasce do princípio da isonomia, ou seja, o Estado deve tratar igualmente seus cidadãos.

Ao seu turno, Meirelles Teixeira ${ }^{24}$ assevera que os direitos fundamentais são anteriores e superiores ao próprio Estado. O Estado em face destes direitos é obrigado a ceder garantias inerentes aos homens. Afirma serem direitos inatos, pois aos homens são conferidos simplesmente através do fato de obterem vida, isto é, nascer e existir. Também, informa que há entre estes direitos os de caracteres político, o homem exerce como cidadão; o social, nas prestações positivas do Estado com o fim de proporcionar aos homens os meio indispensáveis ao pleno exercício das liberdades; e, o institucional, que reflete a proteção dada às instituições. Entretanto, salienta que são direitos fundamentais somente aqueles que valer como anteriores e superiores ao Estado.

\section{Concepções sobre a liberdadade ao longo da história}

Haja vista que a liberdade é um direito fundamental básico, de primeira geração, detentora das prerrogativas que Ihe são inerentes face sua categoria, analisemos sua natureza e as veredas percorridas até atingir seu estado atual.

A liberdade é inerente ao homem, ela é anterior à Sociedade, ao Direito e ao Estado. Ela foi concebida ao homem desde a sua formação. A liberdade é imanente à natureza humana. O Estado a reconhece, a regula e restringe seu uso pelo homem.

Várias acepções são dadas à palavra liberdade. Uns a definem como oposição ao autoritarismo, ausência de coação. Há quem a conceitue em razão do seu exercício, fazer aquilo que Ihe apraz. Também pode ser expressa pelo antagonismo de cativeiro ou a participação no exercício do Poder, entre outros.

Afonso da Silva ${ }^{25}$ aduz que liberdade consiste na "possibilidade de coordenação consciente dos meios necessários à realização da felicidade pessoal”.

Para Montesquieu ${ }^{26}$, a liberdade consiste em poder fazer o que as leis permitem, a liberdade da Constituição é fundamento da liberdade do cidadão, em suas próprias palavras:

\footnotetext{
24 MEIRELLES TEIXEIRA, J. H. Curso de direito constitucional. Rio de Janeiro: Forense Universitária, 1991. p. 690-695.

25 SILVA, 2002. p. 232.
} 
"A liberdade é o direito de fazer tudo quanto as leis permitem; e, se um cidadão pudesse fazer o que elas proíbem, não mais teria liberdade, porque os outros teriam idêntico poder."

A liberdade pode ser distinta pela seguinte dicotomia: liberdade interna e liberdade externa. A primeira é subjetiva, a liberdade moral, "é o livre-arbítrio, como simples manifestação da vontade no mundo interior do homem ${ }^{27 "}$, a outra liberdade é objetiva, e consiste na reprodução externa do querer pessoal, é a liberdade de poder fazer, mas esta liberdade "implica o afastamento de obstáculo ou coações, de modo que o homem possa agir livremente".

Corrêa ${ }^{28}$ contrasta bem estas duas liberdades, ensinando que: Enquanto a liberdade interna é ampla e abstrata, a liberdade externa é restrita e objetiva. Por isso, esta vem sempre ligada a uma limitação legal, visualizando não só o bem de um, mas de todos; não o bem do indivíduo, isoladamente, mas do indivíduo dentro de um contexto social.

O homem ao optar por viver em uma sociedade politicamente organizada teve a necessidade de aprender a conciliar a sua liberdade individual à regulamentação da Liberdade. Rousseau ${ }^{29}$ sustenta esta conciliação através do pacto social de forma a que "cada um de nós coloca em comum a sua pessoa e todo o seu poder sobre a suprema direção da vontade geral, e nós recebemos em corpo cada membro como parte indivisível do todo".

Torna-se perigosa esta afirmação se não for respeitada a liberdade interior. Rabello ${ }^{30}$ advoga que "as restrições ou limitações existentes são ditadas apenas por força de superiores razões de capacidade e estados político, familiar ou individual, reconhecida e assegurada, porém, em qualquer circunstância, a liberdade interior".

Por ser a liberdade uma das protagonistas dos direitos fundamentais, ela passou pelo mesmo desenvolvimento histórico mencionado anteriormente em face destes direitos. Porém, com algumas particularidades, veremos agora quais são essas individualidades. 0 Estado Antigo não reconhecia o direito de liberdade, com raríssimas exceções a liberdade

26 CHEVALIER, Jean Jacques. As grandes obras políticas de Maquiavel a nossos dias. Trad. Lydia Cristina. 8.ed. Rio de Janeiro: Agir, 1998. p. 139.

27 SILVA, 2002. p. 230-231.

28 CORRÊA, Plínio de Oliveira. Liberdade individual nos países do Mercosul. Porto Alegre: Livraria do Advogado, 1995. p. 15

29 CHEVALIER, 1998. p. 166.

30 RABELLO, José Geraldo de Jacobina. Alienação fiduciária em garantia e prisão civil do devedor. 2.ed. São Paulo: Saraiva, 1987. p. 6. 
teve guarida na célebre fase da República Romana e na não menos áurea Democracia Ateniense.

O primeiro controle jurisdicional prisional foi com o Estatuto da Paz, Carta editada pelo Rei Luiz VI, o Gordo (1108-1137), de França, em que dizia: “Ninguém poderá prender qualquer pessoa, livre ou serva, sem a intervenção do juiz; se este não aparecer, o indiciado réu poderá ser detido até ele chegar ou conduzido à sua casa ${ }^{31 ” .}$.

$\mathrm{Na}$ Inglaterra, em 1679, no reinado de Carlos II, surgiu o remédio jurídico que iria influenciar o ordenamento de vários outros povos, o Habeas Corpus Act, medida que cessa a decretação da prisão infundada. Todavia, este habeas corpus somente era destinado a pessoas que eram acusadas de crime, assim, em 1816, durante reinado de Jorge III, o Parlamento britânico ampliou a aplicação deste remédio contra a prisão de qualquer origem.

Nos Estados Unidos da América, em 1789, a Constituição foi acrescida de dez Emendas, que continham Declarações de Direitos (Bill of Rights), dentre essas declarações foi confirmado o habeas corpus.

A Declaração Universal dos Direitos Humanos aprovada pela Assembléia Geral das Nações Unidas em 1948 em seu art. 1ํ expressa a liberdade ao ratificar que todos homens nascem livres e iguais em dignidade e direitos, ainda o art. 3 diz que todo homem tem direito à vida, à liberdade e à segurança pessoal.

No Brasil podemos indicar o marco inicial desta busca à liberdade o ano de 1789, a partir da Inconfidência Mineira, pois se clamava um forte grito de liberdade contra o despotismo da Metrópole e em seguida explodia na Inconfidência Baiana, de 1798. Após a Independência, a primeira Carta Constitucional, de 1824, em seu Título VIII, rezava sobre as garantias dos direitos civis e políticos dos cidadãos brasileiros e tinha por fundamento a liberdade. $\mathrm{O}$ inc. VIII, do art. 179, constava que ninguém poderia ser preso sem culpa formada, sem ordem escrita de autoridade e ao juiz era obrigado contar ao réu o motivo de sua prisão, o nome do acusador e suas testemunhas, salvo nos casos de flagrante delito (inc. X, art. 179). E o Código de Processo Penal de 1832 trouxe o habeas corpus.

31 CORRÊA, 1995. p. 17. 
O mestre italiano Beccaria ${ }^{32}$, ao tratar sobre o direito de punir leciona que foi a necessidade que "impeliu os homens a ceder parte da própria liberdade. É certo que cada um só quer colocar no repositório público a mínima porção possível, apenas a suficiente para induzir os outros a defendê-lo. O agregado dessas mínimas porções possíveis é que forma o direito de punir.

O resto é abuso e não justiça. E completa o raciocínio, aduzindo que: "Eis, então, sobre o que se funda o direito do soberano de punir os delitos: sobre a necessidade de defender o depósito da salvação pública das usurpações particulares. Tanto mais justas são as penas quanto mais sagrada e inviolável é a segurança e maior a liberdade que o soberano dá aos súditos".

Ao cedermos o quinhão de nossa liberdade quando decidimos viver em sociedade legitimamos que o Estado administre as possíveis usurpações destas liberdades. Eis que aparece o Direito munido de suas sanções, pois de outra forma o Estado seria inoperante.

$\mathrm{Na}$ esteira da liberdade, a concepção de maior valor para a matéria que ora estudamos é a noção de liberdade oposta ao cativeiro. Ou seja, a liberdade da pessoa física que é antagônica ao estado de escravidão e prisão ou qualquer empecilho à locomoção pessoal.

Afonso da Silva ${ }^{33}$ distingue a liberdade física em liberdade de locomoção e liberdade de circulação. Liberdade de locomoção é o direito de ir e vir, ficar, permanecer, sendo desnecessária a autorização, podendo locomover livremente sem que privem este direito. Por seu turno, o direito de circulação é a "manifestação característica da liberdade de locomoção: direito de ir, vir, ficar estacionar [...] na faculdade de deslocar-se de um ponto a outro através de uma via pública ou afetada ao uso público".

Atualmente é indiscutível que o habeas corpus também seja o remédio hábil para combater prisão decretada de forma ilegítima ou por abuso de poder. Toda e qualquer coação infundada sobre a liberdade de locomoção do indivíduo é passível de ser combatida com este remédio constitucional. O jurista Marmitt $^{34}$ ao expressar sobre a natureza do habeas corpus assevera que a mesma "não varia quanto à sua incidência no cível ou no

\footnotetext{
32 BECCARIA, Cesare. Dos delitos e das penas. Trad. José Cratella Júnior e Agnes Cretella. 2.ed. 2.tir. São Paulo: Revista dos Tribunais, 1999. p. 28-29.

33 SILVA, 2002. p. 236-239.

34 MARMITT, Arnaldo. Prisão civil por alimentos e depositário infiel. Rio de Janeiro: Aide, 1989. p. 47. 
crime. Sua habilidade e eficácia para desconstituir decisões criminais, valerá também para a obtenção do mesmo efeito relativamente às decisões prolatadas na esfera cível".

Tanto a Constituição Federal ${ }^{35}$, bem como o Código de Processo Penal (Art. 647) nada exprimem sobre a origem da coação que tanto pode ser de iniciativa cível ou criminal. Afirma, ainda, Marmitt ${ }^{36}$ que decretada a prisão por juiz de primeiro grau, o agravo de instrumento será o instrumento adequado para relaxar a prisão. Porém, ressalta que com a formalidade da tramitação do agravo se gasta um tempo dilatado, o que torna inoperante o recurso. Assim, a lacuna deixada pela legislação processual é preenchida pelo habeas corpus, "vez que se trata de um remédio idôneo e expedido para substituir com perfeição o agravo".

Ainda quanto ao remédio bretão, Costa $^{37}$ (apud MAZZUOLI, 1999, p. 73) diz que "não há como se negar que entre a prisão civil e a prisão criminal existe inevitável analogia, uma vez que ambas importam em cerceamento da liberdade".

\section{Conclusões}

Ao bem da verdade, qualquer modalidade de prisão ou ato que culmine na cessação da liberdade física do indivíduo, dilacera e impõe sofrimento. Não há motivos de louvor na atitude de encarcerar o ser humano, como podemos observar através de Foucault ${ }^{38}$, mesmo sendo este pensador um epistemólogo, numa das raras críticas aduz que "se é verdade que a prisão sanciona a delinqüência, esta no essencial é fabricada num encarceramento e por um encarceramento que a prisão no fim de contas continua por sua vez".

A prisão não só encarcera o ser humano, mas cativa a sua alma.

Seguindo esta seara, a liberdade somente pode ser suprimida de qualquer ser humano em ultima ratio, devendo sempre serem observados os princípios garantistas consignados na Lei Maior e a posição de estirpe em que se encontra a Liberdade frente ao Estado Democrático de Direito.

\footnotetext{
35 Art. 5o, inc. LXVIII, CF. "Conceder-se-á habeas corpus sempre que alguém sofrer ou se achar ameaçado de sofrer violência ou coação em sua liberdade de locomoção, por ilegalidade ou abuso de poder."

36 MARMITT, 1989. p. 44-47.

37 COSTA APUD MAZZUOLI, Valério de Oliveira. Alienação fiduciária em garantia e a prisão do devedorfiduciante: uma visão crítica à luz dos direitos humanos. Campinas: Agá Júris, 1999. p. 73.

38 FOUCAULT, Michel. Vigiar e punir. Trad. Raquel Ramalhete. 26. ed. Petrópolis: Vozes, 2002. p. 249.
} 


\section{Referências}

ALMEIDA, José Ferreira de. A Bíblia Sagrada. 2.ed. São Paulo: Sociedade Bíblica do Brasil, 1996.

BASTOS, Celso Ribeiro. Curso de direito constitucional. 20. ed. São Paulo: Saraiva, 1999.

BECCARIA, Cesare. Dos delitos e das penas. Trad. José Cratella Júnior e Agnes Cretella. 2.ed. 2.tir. São Paulo: Revista dos Tribunais, 1999.

BOBBIO, Norberto. A era dos direitos. Trad. Carlos Nelson Coutinho. 12. ed. Rio de Janeiro: Campus, 1992.

CANOTILHO, José Joaquim Gomes. Direito constitucional e teoria da constituição. Coimbra: Almedina, 1997.

CHEVALIER, Jean Jacques. As grandes obras políticas de Maquiavel a nossos dias. Trad. Lydia Cristina. 8. ed. Rio de Janeiro: Agir, 1998.

CNBB, Coordenadoria Ecumênica de Serviço. Declaração universal dos direitos humanos. 3. ed. São Paulo: Paulinas, 1978.

CORRÊA, Plínio de Oliveira. Liberdade individual nos países do Mercosul. Porto Alegre: Livraria do Advogado, 1995.

FOUCAULT, Michel. Vigiar e punir. Trad. Raquel Ramalhete. 26. ed. Petrópolis: Vozes, 2002.

GARCIA, Maria. Mas, quais são os direitos fundamentais?. Revista de Direito Constitucional e Internacional. São Paulo, n. 39, p. 115-123, 2002.

GONÇALVES, Flávio José Moreira. Notas para a caracterização epistemológica da teoria dos direitos fundamentais. In: GUERRA FILHO, Willis Santiago. Dos direitos humanos aos direitos fundamentais. Porto Alegre: Livraria do Advogado, 1997. p. 31-43.

GUERRA, Marcelo Lima. Direitos fundamentais e a proteção do credor na execução civil. São Paulo: Revista dos Tribunais, 2003.

LOPES, Ana Maria D'Ávila. Hierarquização dos direitos fundamentais?. Revista de Direito Constitucional e Internacional, São Paulo, n. 34, p. 168-163, 2001.

MARMITT, Arnaldo. Prisão civil por alimentos e depositário infiel. Rio de Janeiro: Aide, 1989. 
MAZZUOLI, Valério de Oliveira. Alienação fiduciária em garantia e a prisão do devedorfiduciante: uma visão crítica à luz dos direitos humanos. Campinas: Agá Júris,1999.

MEIRELLES TEIXEIRA, J. H. Curso de direito constitucional. Rio de Janeiro: Forense Universitária, 1991.

MIRANDA, Jorge. Manual de direito constitucional. 3. ed. tomo. IV. Coimbra: Coimbra, 2000.

MORAES, Guilherme Peña de. Direitos fundamentais: conflitos e soluções. Niterói: Labor Júris, 2000.

RABELLO, José Geraldo de Jacobina. Alienação fiduciária em garantia e prisão civil do devedor. 2.ed. São Paulo: Saraiva, 1987.

SILVA, José Afonso da. Curso de direito constitucional positivo. 20. ed. São Paulo: Malheiros, 2002. 
Revista de Direito Público, Londrina, v. 1, N. 2, P. 137-150, MAio/Ago. 2006. 